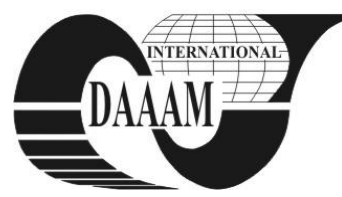

Annals of DAAAM for 2011 \& Proceedings of the 22nd International DAAAM Symposium, Volume 22, No. 1, ISSN 1726-9679 ISBN 978-3-901509-83-4, Editor B. Katalinic, Published by DAAAM International, Vienna, Austria, EU, 2011 Make Harmony between Technology and Nature, and Your Mind will Fly Free as a Bird

Annals \& Proceedings of DAAAM International 2011

\title{
MAXIMIZATION OF THE ENERGY OF A WIND SYSTEM WITH A SYNCHRONOUS GENERATOR
}

\author{
BABESCU, M[arius]; BOTA, C[onstantin] \& CARUNTU, B[ogdan]
}

\begin{abstract}
In this paper an optimal working regime for a wind system (wind turbine + synchronous generator) is computed by using a control system which maximizes the energy obtained from the turbine for a variable wind velocity. The effectiveness of the method proposed here is evaluated by calculating the corresponding energy for several different wind velocities.

Key words: synchronous generator, wind system, mathematical model, maximal energy
\end{abstract}

\section{INTRODUCTION}

The system considered here is composed from a wind turbine and a synchronous generator (denoted in the following by WT and SG, respectively) (Li et al., 2009). Such a system (Mikhailov et al., 2010) is usually designed for a medium wind speed. When a control for such a wind system is designed the meteorological information is taken into account but the momentary speed of the wind is usually not (Fan et al., 2009), and this omission may lead to a reduced total power.

The present paper introduces a possible implementation for the control of the load of a SG which maximizes the electrical power. Our control procedure is based on an estimation of the momentary speed of the wind.

\section{MATHEMATICAL MODEL}

The mathematical models for the synchronous generator (SG) with permanent magnets consists, in the orthogonal model, of the following system of differential equations (Baratky et al., 2009; Hu et al., 2009; Muyeen et al., 2009):

$$
\left\{\begin{array}{c}
-R \cdot I_{d}=1.6 \cdot I_{d}+0.07 \cdot \frac{d I_{d}}{d t}-\omega \cdot 0.08 \cdot I_{q} \\
-R \cdot I_{q}=\omega \cdot 0.07 \cdot I_{d}+1.6 \cdot I_{q}+0.08 \cdot \frac{d I_{q}}{d t}+\omega \cdot 1.3 \\
M_{S G}=I_{q} \cdot \Psi_{M P}
\end{array}\right.
$$

where $R$ is the load resistance of SG, $\Psi_{M P}=1.3[\mathrm{~Wb}]$ is the flux of the permanent magnet, $L_{d}=0.07[H]$ is the inductance on the d axis, $L_{q}=0.08[H]$ is the inductance on the $\mathrm{q}$ axis and $M_{S G}$ is the torque of SG.

The wind turbine (WT) is connected to SG through a reductor with the transmission ratio $K_{T}=314 / 20$. The mathematical model of the WT (its mechanical characteristic) is given by the equation :

$$
M_{W T}=a \cdot \omega_{W T}+b \cdot V^{1.5}
$$

or

$$
M_{W T}=-0.5 \cdot \frac{\omega}{K_{T}}+20 \cdot\left(\frac{V}{5}\right)^{1.5}=-\frac{10}{314} \omega+20 \cdot\left(\frac{V}{5}\right)^{1.5}
$$

The torque WT with respect to the axis of SG is :

$$
M_{S G}=\frac{20}{314}\left[-\frac{10}{314} \omega+20 \cdot\left(\frac{V}{5}\right)^{1.5}\right]
$$

Thus the equation of the movement becomes :

$5 \cdot \frac{d \omega}{d t}=1.3 \cdot I_{q}+\frac{20}{314} \cdot\left(-\frac{10}{314} \cdot \omega+20 \cdot(5+3 \cdot \operatorname{Sin}(0.3 \cdot t))^{1.5}\right)$

For different initial values of $\mathrm{R}$, the system is solved numerically by using a predictor-corrector-type method on the interval $[0, T]$, where $\mathrm{T}$ is of the order of weeks, and the corresponding value of the electrical energy yielded by the system is computed using the formula

$$
W=\int_{0}^{T} P d t=\int_{0}^{T} R \cdot\left(I_{d}{ }^{2}+I_{q}^{2}\right) d t
$$

Next we determine a set of points $(\mathrm{R}, \mathrm{W})$ from the graphical representation of $\mathrm{W}=\mathrm{W}(\mathrm{R})$.

Using a fitting procedure for the set of points $(\mathrm{R}, \mathrm{W})$ we can compute an approximate polynomial expression for $\mathrm{W}=\mathrm{W}(\mathrm{R})$.

We determine the maximum of this function. The corresponding value of $\mathrm{R}$ is the optimal value Ropt for which the electrical energy yielded by the system reaches its maximum.

The study is performed on the $[0, T]$ interval. First we determine the optimal value of the load resistance corresponding to a fixed wind speed such that the energy of the system is maximized for the given speed.

\section{NUMERICAL RESULTS}

In the computation of the load resistance $\mathrm{R}$ which maximizes the electrical energy obtained, we analyze the following cases of the variation of the wind velocity with the time :

3.1 Case A - Variation of the mean velocity: We consider the following values :

1) $V=5+3 \cdot \operatorname{Sin}(0.3 \cdot t)$; 2) $V=8+3 \cdot \operatorname{Sin}(0.3 \cdot t)$;

3) $V=11+3 \cdot \operatorname{Sin}(0.3 \cdot t)$; 4) $V=14+3 \cdot \operatorname{Sin}(0.3 \cdot t)$;

5) $V=17+3 \cdot \operatorname{Sin}(0.3 \cdot t)$

For a time interval of 14 days we selected as the working interval for $\mathrm{R}$ the interval $\mathrm{I}=[0,4000]$.

In the case A1, we performed the computations for a number of 20 values of $R$, selected as a equidistant partition of the interval I. For the set of points $(\mathrm{R}, \mathrm{W})$ obtained we computed a 10th degree approximate polynomial expression for the function $\mathrm{W}=\mathrm{W}(\mathrm{R})$ by using a fitting procedure. The set of points, together with the corresponding fitting polynomial, are presented in the Figure 1.

By computing the maximum of the approximate polynomial expression of the function $\mathrm{W}=\mathrm{W}(\mathrm{R})$ we obtained the maximal 
value of the energy $W \max =1.7181 \times 10^{10}$ and the corresponding value of the optimal load resistance Ropt $=$ 716.97.

We performed the same type of computations for the other cases A2 - A5, and the graphical representation of the total energy as a function of the load resistance is presented in Figure 2.

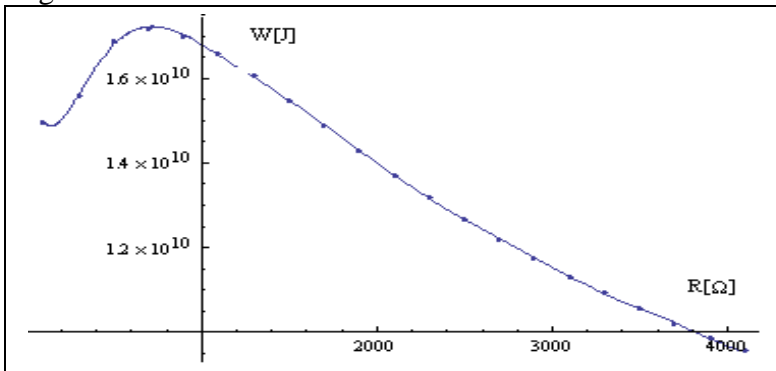

Fig. 1. The dependence of the energy on the load resistance for the case A1

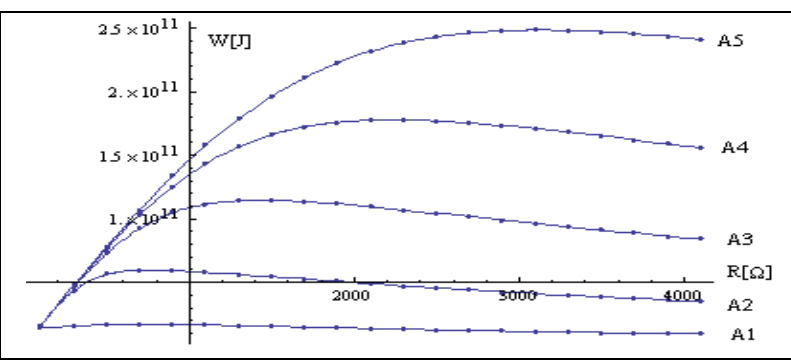

Fig. 2. The dependence of the energy on the load resistance for the cases A1 - A5

In Figure 2, the lowermost curve corresponds to the case A1), the one above it to the case A2) and so on (in increasing order), the topmost one corresponding to the case A5).

For each curve we used a fitting polynomial and we computed the maximal value of the energy Wmax and the corresponding value of the optimal value of the load resistance Ropt. The values obtained for Ropt are presented in Table 1:

\begin{tabular}{|l|l|l|}
\hline Case & Wmax & Ropt [ $\Omega$ ] \\
\hline A1 & $1.7181 \times 10^{10}$ & 716.97 \\
\hline A2 & $5.9504 \times 10^{10}$ & 748.651 \\
\hline A3 & $1.1448 \times 10^{11}$ & 1430.62 \\
\hline A4 & $1.7775 \times 10^{11}$ & 2234.95 \\
\hline A5 & $2.4836 \times 10^{11}$ & 3120.18 \\
\hline
\end{tabular}

Tab. 1. Optimal value of the load resistance for the Case A

3.2 Case B - variation of the amplitude of the velocity :

1) $V=17+3 \cdot \operatorname{Sin}(0.3 \cdot t)$; 2$) V=17+5 \cdot \operatorname{Sin}(0.3 \cdot t)$

3) $V=17+7 \cdot \operatorname{Sin}(0.3 \cdot t)$; 4) $V=17+9 \cdot \operatorname{Sin}(0.3 \cdot t)$

5) $V=17+11 \cdot \operatorname{Sin}(0.3 \cdot t)$; 6) $V=17+13 \cdot \operatorname{Sin}(0.3 \cdot t)$

We selected as the working interval for $\mathrm{R}$ the interval $[0$, 5000]. The graphical representation of the total energy as a function of the load resistance is presented in Figure 3. In this figure, the lowermost curve corresponds to the case B1), the one above it to the case B2) and so on (in increasing order).

The maximal values of the energy and the corresponding values of the optimal value of the load resistance are:

\begin{tabular}{|l|l|l|}
\hline Case & Wmax & Ropt [ $\Omega$ ] \\
\hline B1 & $2.4836 \times 10^{11}$ & 3120.18 \\
\hline B2 & $2.5125 \times 10^{11}$ & 3158.06 \\
\hline B3 & $2.5556 \times 10^{11}$ & 3213.51 \\
\hline B4 & $2.6160 \times 10^{11}$ & 3287.98 \\
\hline B5 & $2.6918 \times 10^{11}$ & 3382.46 \\
\hline B6 & $2.7832 \times 10^{11}$ & 3498.09 \\
\hline
\end{tabular}

Tab. 2. Optimal value of the load resistance for the Case B

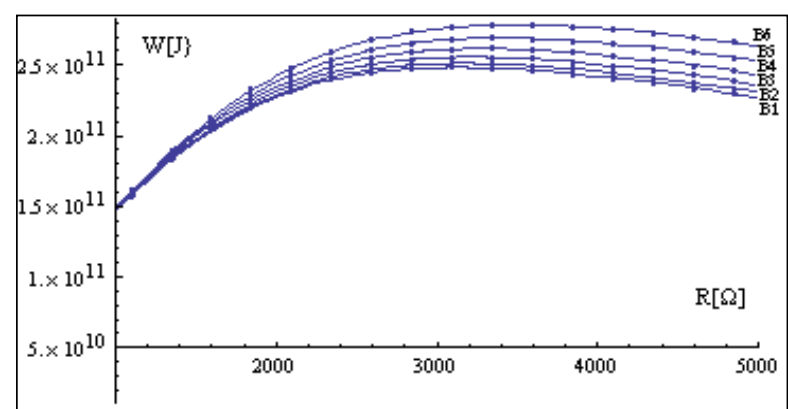

Fig. 3. The dependence of the energy on the load resistance for the cases A1 - A5

\section{CONCLUSIONS}

Our study shows that the electrical energy obtained by using a WT + SG wind system can be significantly increased by taking into account the velocity of the wind.

The maximal energy corresponds to a well determined optimal value of the load resistance connected to the SG, resistance which depends on the wind velocity.

If we use an estimation for the wind velocity of the form $V=A+B \cdot \operatorname{Sin}(0.3 \cdot t)$, larger values for either A or B lead to an increase of the total energy. We remark that both the optimal load resistance Ropt and the maximal energy obtained Wmax depend in a significant way on the mean velocity $A$. The dependence on the amplitude $B$ is not so strong, and thus the control system can be optimally designed from the point of view of the energy by taking into acount the mean velocity.

The main limitation of the study consists in the fact that we considered only wind velocities of the type $A+B \cdot \operatorname{Sin}(0.3 \cdot t)$.

A future research direction could be the implementation of alternate estimations for the wind velocity and the investigation of their effect on the variation of the energy.

\section{REFERENCES}

Baratky, S.M.; Kazerani, M. \& Aplevich, J.D. (2009). Maximum Power Tracking Control for a Wind Turbine System Including a Matrix Converter, IEEE Trans. Energy Convers., vol. 24, no. 3, September 2009, pp.705-713, ISSN 0885-8969

Fan, S.; Liao, J.R.; Yokohama, R.; Chen, L. \& Lee, W.-J. (2009). Forecasting the Wind Generation Using a TwoStage Network Based on Meteorological Information, IEEE Trans. Energy Convers., vol. 24, no. 1, March 2009, p. 474482, ISSN 0885-8969

Hu, W.; Chen, Z.; Wang, Y. \& Wang, Z. (2009). Flicker Mitigation by Active Power Control of Variable -Speed Wind Turbines With Full-Scale Back-to-Back Power Converters, IEEE Trans. Energy Convers., vol. 24, no. 3, September 2009, p.640-649, ISSN 0885-8969

Li, H.; Chen, Z. \& Polinder H. (2009). Optimization of Multibrid Permanent-Magnet Wind Generator Systems, IEEE Trans. Energy Convers., vol. 24, no. 1, March 2009, p.82-92, ISSN 0885-8969

Mikhailov, M.; Kopychev, V.; Larchikov, I.; Kopaev, S.; Cvet kov, V. \& Stazhkov, S. (2010). Application of Hydromechanical Constant Speed Drives in a Wind Power Generation System, Annals of DAAAM for 2010 \& Proceedings of the 21st International DAAAM Symposium, 20-23rd October 2010, Zadar, Croatia, ISSN 1726-9679, ISBN 978-3-901509-73-5, Katalinic, B. (Ed.), pp. 02990300, Published by DAAAM International Vienna, Vienna

Muyeen, S.M.; Takahashi, R.; Murata, T. \& Tamura, J. (2009). Integration of an Energy Capacitor System With a Variable-Speed Wind Generator, IEEE Trans. Energy Convers., vol. 24, no. 3, September 2009, p.740-749, ISSN 0885-8969 